\title{
Headed studs close to the concrete edge under pull-out
}

\author{
A. M. Pascual ${ }^{\text {**, U. Kuhlmann }}{ }^{\text {, J. Ruopp }}{ }^{\text {a }}$ and L. Stempniewski ${ }^{\text {a }}$ \\ ${ }^{a}$ Institut für Konstruktion und Entwurf, Universität Stuttgart, Germany \\ *corresponding author, e-mail address: ana.pascual@ke.uni-stuttgart.de
}

\begin{abstract}
The capacity of the headed studs when they are close to the edge may be limited by the splitting forces in the concrete. In the Eurocode 4 Part 2 Annex $C$ the shear capacity under this particular arrangement of the studs, which is directly dependent on the distance to the edge, is formulated. In addition, the geometrical restrictions to prevent the failure by pullout of the studs are also given in clause C1 (2). These rules are based on push-out tests for the edge position where tension forces in the lying studs spread over the width of the specimen in this unfavorable way. Nonetheless, the current limits lead to extremely long studs and represent a severe restriction, and on the other hand, it is still an open question whether in real buildings or bridge girders the tension stresses that produce the pull-out appears in the same way as in the push out tests. In this paper the revision of these restrictions is presented together with a research for the alternative use of EN 1992-4 plus RFCS Project INFASO for the verification of the tension loads on the studs.
\end{abstract}

Keywords: Headed studs; splitting forces; pull-out; edge position; shear capacity.

\section{Introduction}

Headed studs close to the concrete edge allow interesting forms of construction, such as building edge beams in car park construction or slimfloor beams [1]. In bridge construction, the horizontal studs may serve to longitudinally connect the steel girder to the concrete slab as for example in an arch bridge. Similarly, a double layer of horizontal studs represents the connection steelconcrete in an innovative design of composite bridge girder, where the upper flange of the steel girder has been replaced by the studs (Fig. 1 and Fig. 2)[2],[3]. For this section girder design, the studs are arranged in a lower layer embedded into a prefabricated concrete slab and an upper layer in concrete in in-situ. The advantages of this configuration come from the reduction in the steel consumption together with the constructional advantages of prefabrication. An additional improvement of the transversal bending capacity and longitudinal connection can be achieved by using a corrugated steel web for the girder [2],[3].

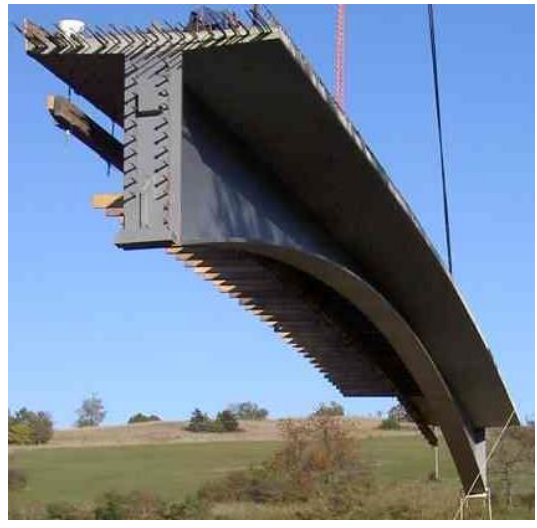

Fig. 1. Prefabricated composite bridge girder with horizontally lying studs [2],[3]

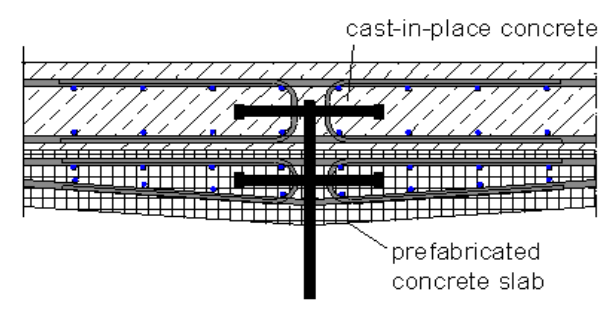

Fig. 2. New section with two layers of horizontally lying studs [2],[3] 
A main aspect to consider when studs are close to the edge is the reduction of the connection capacity due to the splitting forces whether the stud is in vertical or horizontal position (Fig. $3)$. There are different geometrical parameters that influence the behavior of the stud connection, but the most important one is the effective edge distance $a_{r}$, which is the distance between the bolt axis and the axis of the reinforcement (Fig. 3 and Fig. 4). Additionally, it is necessary to distinguish between middle and edge position of the connection, since the edge position is more unfavorable due to the possible tensional forces on the studs, not balanced as in the middle position.

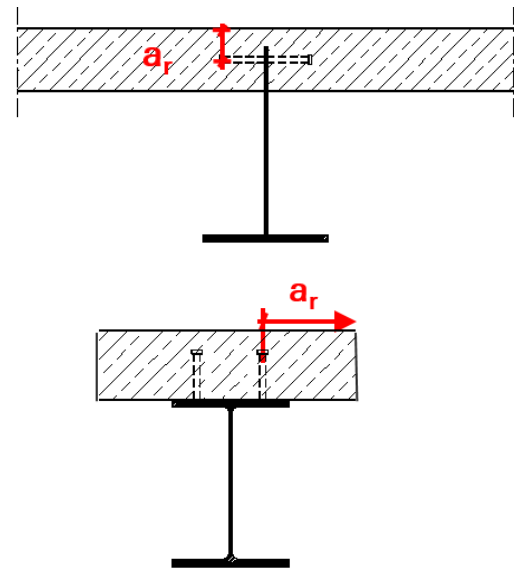

Fig. 3. Headed studs close to the edge.

\section{State of the art}

The behavior of the headed studs close to the concrete edge has been the objective of several researches, see [5],[6] as well as [7]- [9] under static longitudinal and vertical shear and the combination of both. The fatigue strength has been also under analysis. Annex C of EN 19942 [10] collects the results of these works, so they can be used in practice.

However, there are still some aspects that require a further study, this is the case of the fatigue strength of the connection under vertical shear, corresponding to the fatigue loading derived from wheel loads. In this framework, a proposal of enhancement of the Annex $\mathrm{C}$ based on the works from [4],[13] has been implemented [14].

Another clause of the Annex C (EN 1994-2) [10] that requires a revision is the one related to the geometrical restrictions for the length of the stud to prevent the pull-out of the headed studs for the case of an edge position, Eq. (1) and Eq. (2).

$\beta \leq 30^{\circ}$ or $v \geq \max \left\{110 \mathrm{~mm} ; 1,7 a_{\mathrm{r}}^{\prime} ; 1,7 \mathrm{~s} / 2\right\}$

$\beta \leq 23^{\circ}$ or $v \geq \max \left\{160 \mathrm{~mm} ; 2,4 a_{\mathrm{r}}^{\prime} ; 2,4 \mathrm{~s} / 2\right\}$

The parameters are defined in Fig. 4 (EN 1994-2) [10]
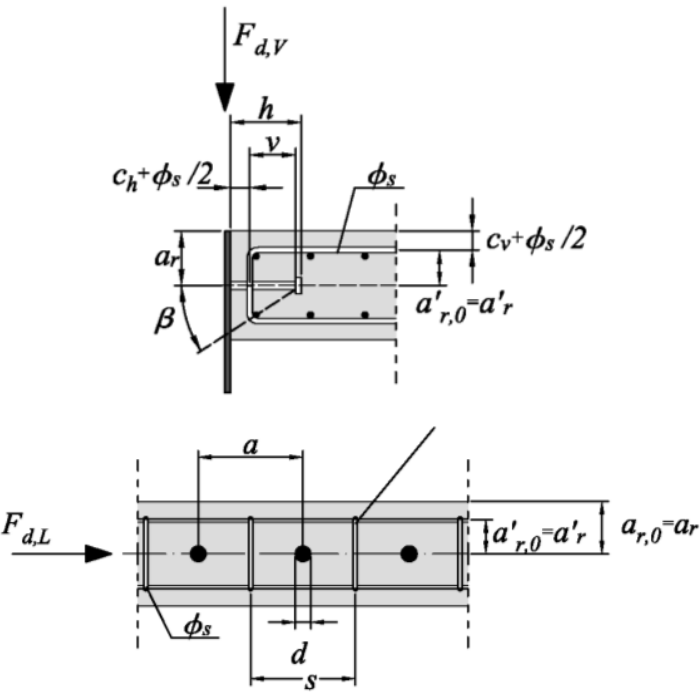

Fig. 4. Position and geometrical parameters of shear connections with studs positioned close to concrete edge (EN 1994-2)[10]

These limitations for the length $\mathrm{v}$ of the headed studs come from the investigations of [6] (Fig. 5) where a premature failure by pull-out of the stud was observed. This should be prevented by a simple safe-sided solution However, the rules may lead to extremely long studs, which are difficult for construction practice.
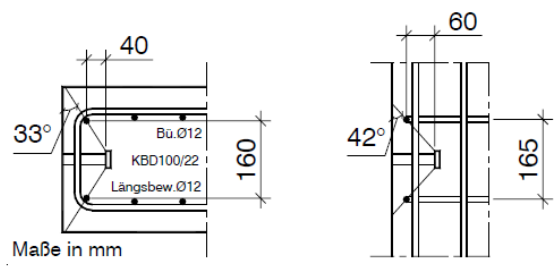

a)

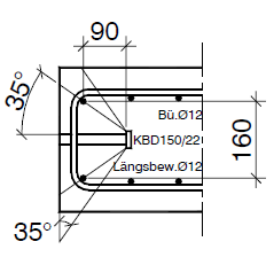

Maße in $\mathrm{mm}$

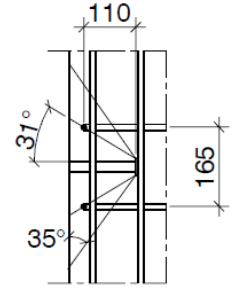

b)
Fig. 5. Pull-out in specimens [6] 
In that regard, the question is whether in real strctures the tension forces occur in the same way as in the conducted experimental tests. In addition, meanwhile the fastening technology represents an alternative for the practicioners EN 1992-4 [12] to verify the pull-out forces and the capacity of the headed studs in tension.

In order to know the tensile forces able to be carried by the headed studs in a thin concrete slab, as correspond to a composite girder design with the namely horizontally lying studs, a preliminar small experimental program was carried out. This paper is devoted to the presentation of the results from the tests and their comparison with the fastening technology EN 1992-4 [12] plus newer approaches according to the RFCS Project INFASO [11] and[16]. In addition a German project [15] has started to develop these solutions covering also the shear loading.

\section{Experiments under pull-out}

An experimental program of 6 specimens under pull-out load was accomplished [16]. The parameters that varied between the different specimens were the length of the headed studs L $(125 / 200 \mathrm{~mm})$, the concrete thickness $\mathrm{t}(250 / 300$ $\mathrm{mm}$ ) and the reinforcement ratio $\mathrm{n}$, see Table 1 .

Table 1. Geometrical parameters of the specimen tests.

\begin{tabular}{cccc}
\hline Test & $\begin{array}{c}\mathrm{L} \\
{[\mathrm{mm}]}\end{array}$ & $\begin{array}{c}\mathrm{t} \\
{[\mathrm{mm}]}\end{array}$ & $\begin{array}{c}\text { Reinforcement } \\
\text { Ratio }\end{array}$ \\
\hline R-1 & 125 & 250 & low \\
R-2 & 125 & 250 & high \\
R-3 & 200 & 250 & low \\
R-4 & 200 & 250 & high \\
R-5 & 200 & 300 & low \\
R-6 & 200 & 300 & high \\
\hline
\end{tabular}

The geometry of the test can be observed in Fig. 6, where the design necessary to apply the load is also shown. The specimens consist of an inverted-T concrete part (see Fig. 6 and Fig. 7) where four headed studs have been embedded. The headed studs were welded to an IPE-profile that is not under analysis, its function is exclusively the load application.

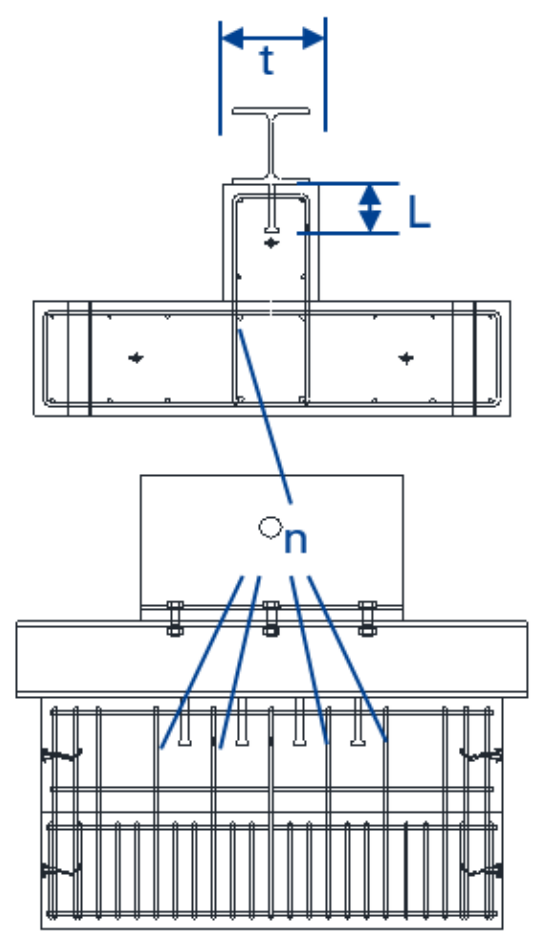

Fig. 6. Geometry of the pull-out specimens [16]

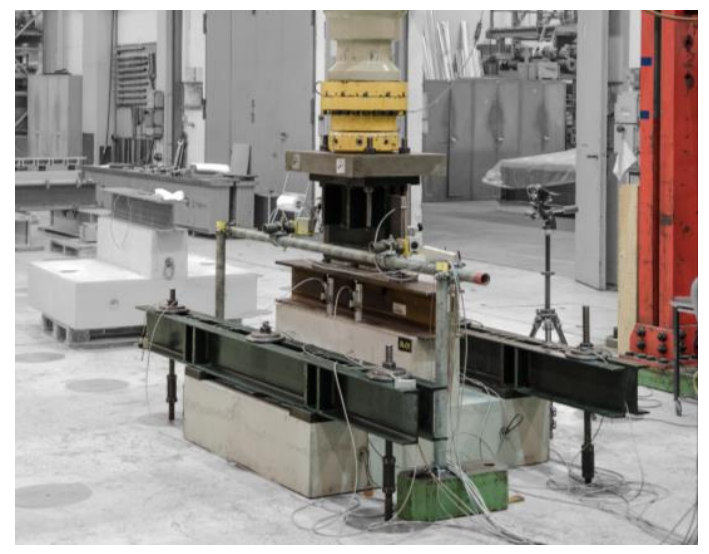

Fig. 7. Set-up of the pull-out tests [16]

From the test results the failure mode according to the different parameters was determined thanks to the force-displacement curve (Fig. 8) together with the strain measurements in headed studs and reinforcement and the visual inspection.

In specimens R-1 and R-2 with shorter headed studs and thiner concrete slab (Table 1), the typical descending branch after the failure by formation of the concrete cone was observed. The specimen R-2 which presents a higher reinforcement gave a higher capacity of the connection. This test specimens failed due to concrete failure between the supplementary reinforcement. 


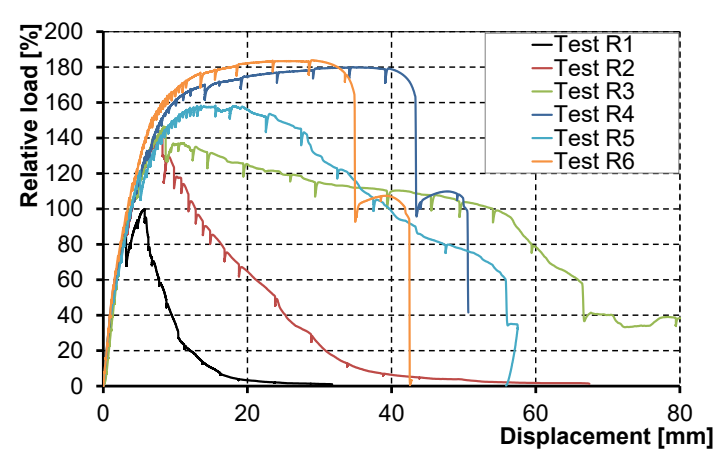

Fig. 8. Curve load (relative to the maximum load of specimen R-1) - displacement from the pullout tests [16]

The specimens R-3 and R-4 introduced longer headed studs and a higher ductility of the connection. For the specimen R-3 the reinforcement was governing the failure and in the case of $\mathrm{R}-4$, with more reinforcement ratio, the headed stud was limiting the connection capacity. Due to the longer embedment depth of the headed studs it has been possible to activate a larger concrete volume. Therefore, the connection beared a higher maximum tensional force.

Finally, specimens R-5 and R-6 with higher thickness of the concrete slab and larger distance to the concrete edge, presented respectively failure of the reinforcement and the concrete and steel failure of the headed stud for the test R-6 with a higher reinforcement ratio.

\section{Application of the fastening technology}

The results from the experiments were compared with the values of capacity given by the fastening technology from EN 1992-4 [12]. Several equations are implemented in the standard corresponding to the different failure mechanisms, nonetheless, the boundary conditions such as the influence of the edge effect on two sides given by a relative small concrete slab and a short distance of the stud to the edge are not specifically considered. So that, with this investigation, the suitability of EN 1992-4 [12] to calculate the capacity of the headed studs under tension in such conditions, can be verified. The failure modes and the corresponding equations (Eq. 3-8) considered by the standard are presented below:

Steel failure of the headed stud (EN 1992-4/ Cl.7.2.1.3):

$N_{R k, s}=\frac{\pi}{4} \cdot d^{2} \cdot f_{u, k}$
Pull-out failure of the headed stud (EN 19924/ C1.7.2.1.4):

$$
N_{R k, p}=k_{1} \cdot \frac{\pi}{4} \cdot\left(d_{h}^{2}-d^{2}\right) \cdot f_{c, k}
$$

Blow-out failure of a headed stud (EN 19924 / Cl.7.2.1.8):

$$
\begin{aligned}
& N_{R k, c b}=N_{R k, c b}^{0} \cdot \frac{A_{c, N} b}{A_{c, N b}^{0}} \cdot \psi_{s, N b} \cdot \psi_{g, N b} \\
& \text { with } N_{R k, c b}^{0}=k_{9} \cdot c_{1} \cdot \sqrt{f_{c k}} \cdot h_{e f}^{1,5} \\
& \text { required if: } \mathrm{c}<0,5 \mathrm{~h}_{\mathrm{ef}}
\end{aligned}
$$

Supplementary reinforcement (EN 1992-4 / Cl.7.2.1.6):

- Yielding of the reinforcement:

$N_{R k, r e}=n_{r e} \cdot A_{s, r e} \cdot f_{y k, r e}$

- Anchorage failure of the reinforcement:

$N_{R k, a}=\sum_{n_{r e}} \frac{l_{1} \cdot \pi \cdot d_{s} \cdot f_{b d}}{\alpha}$

The failure patterns observed in the experiments and the capacity of the connection match with the minimum value calculated with EN 1992-4 [12] except for the cases involving concrete strut failure, see Fig. 9. In those cases the standard is too conservative and the results from INFASO Project [11] have been checked. In that European project new approaches to determine the connection capacity consider the load transfer due to concrete and hanger reinforcement. The comparison of the maximum capacity from the tests with the values from [16] can be observed in Fig. 10, the improvement of the accuracy of the prediction for the cases R-1, R-2 and $\mathrm{R}-5$, with concrete strut failure is considerable.

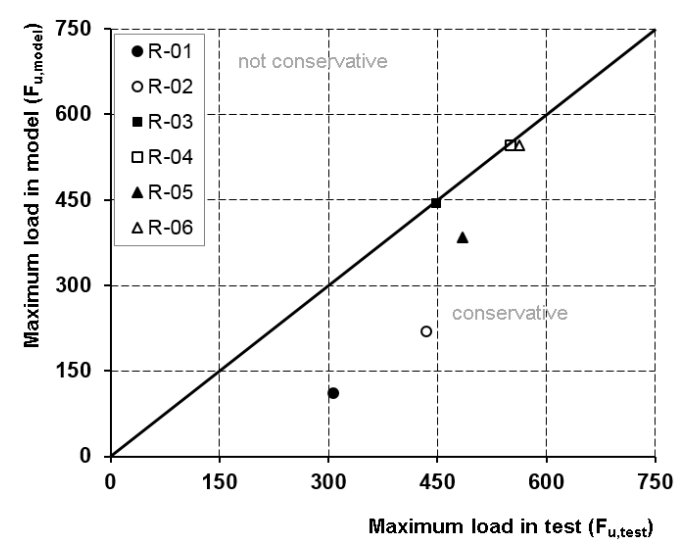

Fig. 9. Comparison maximum load experiments with EN 1992-4 [16] 


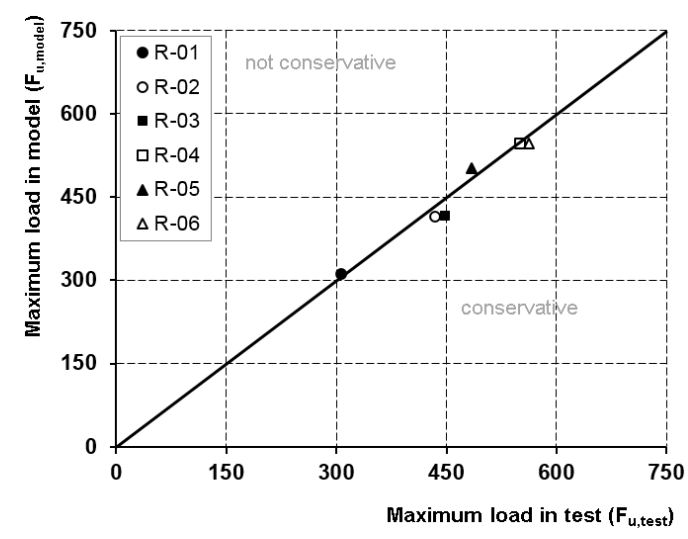

Fig. 10. Comparison maximum load experiments with INFASO [16]

\section{New investigations of the connection under shear}

A German project [15] is now under development with the aim of assessing the tensional forces taken by the studs under longitudinal shear. It includes an experimental program of 9 push-out tests with a similar design to the specimens from Breuninger [6], so that the failure patterns there detected may be revised and the geometrical conditions from EN 1994-2 Annex C [10] readjusted. The specimens try therefore to reproduce the same geometry as the tests from Breuninger [6] and also from the pull-out experimental program [16], in order that the results are comparable.

Table 2. Experimental programm [15].

\begin{tabular}{|c|c|c|c|c|}
\hline Test & $\begin{array}{c}\mathrm{L} \\
{[\mathrm{mm}]}\end{array}$ & $\begin{array}{c}\mathrm{t} \\
{[\mathrm{mm}]}\end{array}$ & $\begin{array}{c}\text { Reinforcement } \\
\text { ratio }\end{array}$ & $\begin{array}{l}\text { Boundary } \\
\text { conditions }\end{array}$ \\
\hline P1 & 125 & 250 & small & $\begin{array}{l}\text { Tension } \\
\text { and shear }\end{array}$ \\
\hline P2 & 125 & 250 & high & $\begin{array}{l}\text { Tension } \\
\text { and shear }\end{array}$ \\
\hline P3 & 200 & 250 & small & $\begin{array}{c}\text { Tension } \\
\text { and shear }\end{array}$ \\
\hline P4 & 200 & 250 & high & $\begin{array}{l}\text { Tension } \\
\text { and shear }\end{array}$ \\
\hline P5 & 200 & 300 & small & $\begin{array}{c}\text { Tension } \\
\text { and shear }\end{array}$ \\
\hline P6 & 100 & 300 & small & $\begin{array}{l}\text { Tension } \\
\text { and shear }\end{array}$ \\
\hline P7 & 100 & 300 & high & $\begin{array}{c}\text { Tension } \\
\text { and shear }\end{array}$ \\
\hline P8 & 125 & 25 & hiş & Shear \\
\hline P9 & 200 & 300 & small & Shear \\
\hline
\end{tabular}

The parameters that varied between the different specimens are shown in Table 2, and are the length of the headed studs L $(100 / 125 / 200$ $\mathrm{mm})$, the concrete thickness $\mathrm{t}(250 / 300 \mathrm{~mm})$ and the reinforcement ratio $\mathrm{n}$. Therefore, in comparison with the experimental program presented in section 4 under tension, the new experimental program presents two specimens with a shorter headed stud $(100 \mathrm{~mm})$ in combination with a larger distance to the concrete edge of the headed stud $(150 \mathrm{~mm})$. These cases are chosen according to [6] as the most unfavorable cases susceptible to fail by pull-out. The boundary conditions for the tests were defined as in Fig. 11, so that, the tension and compression are measured in the headed studs, except for two cases with restricted displacement on the horizontal direction and pure shear loading in the headed studs, Fig. 12.

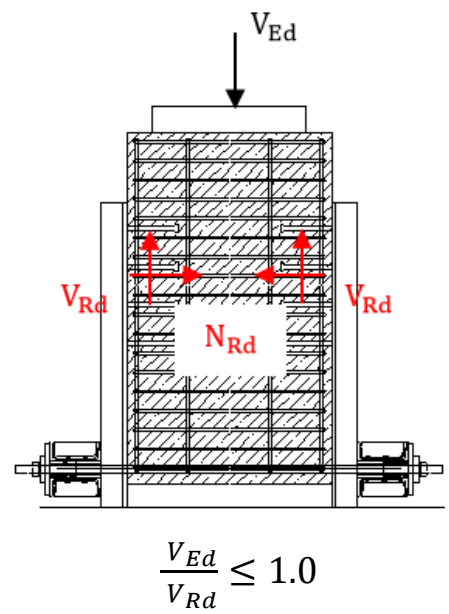

Fig. 11. Test set-up for specimens under shear and tension load

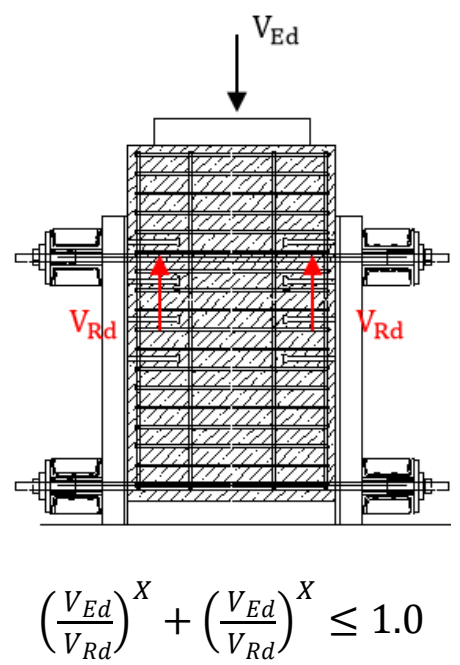

Fig. 12. Test set-up for specimens under shear load [15]

The experimental program is completed with a numerical study by means of FE modelling using the commercial software Abaqus [17]. After the calibration of the model a parametrical study is planned so that more cases may be assessed to 
give the practicioners more reliable criteria to ensure no pull-out failure of the headed studs due to shear loading according to EN 1994-2 Annex $\mathrm{C}$ and to allow for a direct verification of the interaction of shear and tensions forces in slender slabs of composite girders with horizontally lying studs.

\section{Concluding remarks}

This paper is a report of the design restrictions to the headed studs close to the slab edge in EN 1994-2 Annex C. The focus of the research is on the strict geometrical conditions to prevent the pull-out of the headed stud under longitudinal shear (Clause C1(2)) and the required further research. The fastening technology EN 1992-4 [12] is demonstrated to be able to predict the tensile capacity of horizontally lying studs by comparison with a experimental program of pull-out tests. New approaches from INFASO project [11] are proven to be more accurate in the prediction by considering the load transfer due to concrete and hanger reinforcement. A current project [15] is devoted to test the connection not only under pull-out but under longitudinal shear, so that the tension forces on the headed studs can be assessed.

\section{References}

[1] Lam, D, Dai, X, Kuhlmann, U, Raichle, J, and Braun, M. Slim-floor construction - design for ultimate limit state. Steel Construction 2015; 8(2); 79-84.

[2] Kuhlmann, U, Breunig, S, Pascual, AM, Mensinger, M, Pfaffinger, M, Lenz, K, Schneider, S, Beck, T, Ummenhofer, T, Zinke, T: Ganzheitliche Bewertung von Stahl- und Verbundeisenbahnbrücken nach Kriterien der Nachhaltigkeit, FOSTA/ IGF353, P978, 2017.

[3] Kuhlmann U, Raichle J and Pascual AM. Shear connections by headed studs close to the concrete edge". Proceedings of Composite Construction VIII, Jackson Hole, Wyoming, USA, 2017.

[4] Raichle, J. Randnahe Kopfbolzen im Brückenbau. Dissertation, Institute of Structural Design, University of Stuttgart, Issue No. 20152, 2015.

[5] Breuninger, U, and Kuhlmann, U. Tragverhalten und Tragfähigkeit liegender Kopfbolzendübel unter Längsschubbean-spruchung. Stahlbau 2001; 70 (11); 835-845.

[6] Breuninger, U. Zum Tragverhalten liegender Kopfbolzen unter Längsschub-beanspruchung.
Dissertation, Institute of Structural Design, University of Stuttgart, Issue No. 2000-1, 2000.

[7] Kürschner, K. Trag- und Ermüdungsverhalten liegender Kopfbolzen im Verbundbau. Dissertation, Institute of Structural Design, University of Stuttgart, Issue No. 2003-4, 2003.

[8] Kürschner, K, and Kuhlmann, U. Trag- und Ermüdungsverhalten liegender Kopfbolzendübel unter Quer- und Längsschub. Stahlbau 2004; 73(7); 505-516.

[9] Kürschner, K, and Kuhlmann, U. Mechanische Verbundmittel für Verbundträger aus Stahl und Beton. Stahlbaukalender 2005; 455-534.

[10]EN 1994-2. Eurocode 4. Design of composite steel and concrete structures. Part 2: General rules and rules for bridges. Brussels, Belgium: Comité Européen de Normalisation, 2005.

[11] Kuhlmann, U, Hofmann, J, Wald, F, da Silva, L, Krimpmann, M, Sauerborn, N. New market chances for steel structures by innovative fastening solutions between steel and concrete (INFASO). Final report, Report EUR 25100 EN, European Commission, 2012.

[12] EN 1992-4. Eurocode 2, draft. Design of concrete structures - Part 4: Design of fastenings for use in concrete, prEN 1992-4. Brussels, Belgium: Comité Européen de Normalisation; 2015.

[13]Raichle, J, and Kuhlmann, U. Randnahe Kopfbolzen - Ermüdungsverhalten unter Querschub. Stahlbau 2016; 85(2); 153-160.

[14] Kuhlmann, U, Raichle, J, and Pascual, A. Proposal for EN 1994-2 Annex C Headed studs that cause splitting forces in the direction of the slab thickness (Version March 2017), Background Document, sent to Mike Banfi (Project Team PT4.T1), 24-03-2017.

[15]Kuhlmann, U. "Bemessung von Kopfbolzendübeln in Randlage unter Vermeidung eines Versagens infolge Herausziehen" Institut für Konstruktion und Entwurf, Universität Stuttgart. Versuchsbericht, Forschungsprojekt FE 89.0326/2017 im Auftrag der Bundesanstalt für Straßenwesen (BASt), 2017.

[16]Ruopp, J. Untersuchungen zu Anschlüssen zwischen Stahl und Beton unter Querkraftbeanspruchung mit großen Ankerplatten oder mehrseitigem Randeinfluss (Arbeitstitel), Dissertation, Institut für Konstruktion und Entwurf, Universität Stuttgart, geplant 2019.

[17] Pawtucket RIH, Karlsson \& Sorenson, Inc. ABAQUS. ABAQUS/Standard Version 6.6 User's Manual: Volumes V, 2005. 